Article

\title{
Polarimetric Calibration for a Ground-Based Radar, and Comparison of the Polarimetric Parameters with Air-Borne SAR Obtained from a Forest
}

\author{
Manabu Watanabe ${ }^{1, *}$ and Masanobu Shimada ${ }^{1,2}$ \\ 1 Tokyo Denki University, Ishizaka, Hatoyama-machi, Hiki-gun, Saitama 350-0394, Japan; \\ shimada@g.dendai.ac.jp \\ 2 Earth Observation Research Center, Japan Aerospace Exploration Agency, 2-1-1 Sengen, Tsukuba, \\ Ibaraki 305-8505, Japan \\ * Correspondence: 16hz001@ms.dendai.ac.jp; Tel.: +81-49-296-0319
}

Academic Editors: Bruce Chapman, Paul Siqueira, Nicolas Baghdadi, Richard Müller and Prasad S. Thenkabail Received: 27 December 2016; Accepted: 31 March 2017; Published: 3 April 2017

\begin{abstract}
A polarimetric ground-based radar (GB-radar) system operated in the L-band has been developed. The frequency range of GB-radar is 1.215 to $1.3 \mathrm{GHz}$, which is the same as that of Japanese satellite-borne SAR, PALSAR-2 (Phased Array type L-band Synthetic Aperture Radar), and Japanese L-band air-borne radar, i.e., Pi-SAR-L2 (Polarimetric and Interferometric Airborne Synthetic Aperture Radar L2). Polarimetric calibration was carried out twice in the field to calibrate and validate the GB-radar data. Cross-talk and channel imbalance are improved for the both experiments, and are from $-13.3 \mathrm{~dB}$ to $-30.7 \mathrm{~dB}$, and from 1.06 to 1.00 , respectively for the first experiment, after calibration. The calibrated cross-talk and channel imbalance values were comparable to $-31.7 \mathrm{~dB}$ and 1.013, which were obtained using PALSAR. Radiometric calibration and antenna pattern correction were also carried out in the second experiment. Forest observations were also carried out simultaneously by GB-radar and Pi-SAR-L2 in the second experiment. The range profiles obtained by GB-radar and Pi-SAR-L2 were compared for several polarimetric parameters, namely, radar backscattering coefficient, polarimetric coherence, eigenvalue-decomposition parameters, and four-component-decomposition parameters. Both range profiles matched moderately well and showed good performance that could compensate for the limited possibility of satellite/air-borne SAR observation.
\end{abstract}

Keywords: forest monitoring; L-band SAR; ground-based radar; radar calibration

\section{Introduction}

Several papers have noted that radar backscattering $\left(\sigma^{0}\right)$ from a forest exhibits seasonal and temporal variation. Four years of $\sigma^{0}$ variation over a Japanese national forest were examined using PALSAR data [1]. The maximum absolute deviations of $\sigma^{0}$ for the forested area were 1.0 and $1.2 \mathrm{~dB}$ for $\sigma^{0} \mathrm{HH}$ and $\sigma^{0} \mathrm{HV}$, respectively. The authors concluded that the variation was due to the increase in moisture of tree trunks that is often observed after rainfall. Enhanced L-band backscatter following rainfall events was also reported by Lucas et al. [2]. Moisture increase after rainfall for a forested area also affects the L-band SAR interferometry observation. A phase shift of approximately $90^{\circ}$ over a Japanese cedar forest stand was clearly observed for the interferometric pair of March 1 and May 10, 2015, by PALSAR-2. However, no clear phase shift was observed for the adjacent broadleaf forest stand. Except for this pair, no clear phase shift was observed over either cedar or broadleaf forest stands. Heavy rain was observed on 1 March for the forest; this phenomenon is also explained by an increase in tree moisture [3]. 
Since these phenomena are often induced by a rainfall event, the limited possibility for satellite/air-borne SAR observation prevents a complete understanding of the mechanism. GB-radar is a powerful tool for achieving frequent observations using L-band radar, and for compensating for the lack of satellite and air-borne SAR observations, such as PALSAR, PALSAR-2, and Pi-SAR-L2. To realize high frequency observation, GB-radar calibration is essential to comparing and compensating for satellite and air-borne SAR observations. Polarimetric calibration of GB-radar has been successfully performed in an anechoic chamber [4,5]. However, there are few experiments that have carried out polarimetric calibration in the field, or that make comparisons with data obtained by satellite or air-borne SAR data. In this paper, polarimetric GB-radar radiometric calibration, and antenna pattern correction results, are reported. Japanese air-borne SAR (Pi-SAR-L2) data was compared to GB-radar data. GB-radar and Pi-SAR-L2 were used to observe both the 2.5-m corner reflector (CR) and the forested area in the same configuration (incident angle and observation direction) with very similar timing. The range profiles obtained by GB-radar and Pi-SAR-L2 were compared for several polarimetric parameters so as to validate the calibration of the GB-radar data.

\section{Experiments}

\subsection{GB-Radar System}

The GB-radar system consists of a vector network analyzer (VNA), two low-pass filters, two L-band band-pass filters, and two Yagi antennas (Figure 1). Internal calibration for the VNA was done by the manufacturer, Anritsu, on 8 December, 2014. One of the Yagi antennas applied H polarization, and the other applied $\mathrm{V}$ polarization. E plane was set for $\mathrm{H}$ polarization in antenna 1 , and was set for $\mathrm{V}$ polarization in antenna 2 . The $\mathrm{H}$ - and $\mathrm{V}$-polarization antennas were connected to port 1 and port 2 of the VNA. HH polarization measurement was realized at port 1: transmission; and port 1: reception. HV-polarization measurement was realized by port 2: transmission; and port 1: reception, and so on. The reference plane was set at a connector of the antenna, or a tip of the SMA cable. The radar bandwidth of GB-radar was selected as $1.215 \mathrm{GHz}$ to $1.3 \mathrm{GHz}$, which is the same bandwidth as PALSAR-2. The radar transmission bandwidth is set not only by the VNA settings, but also by band-pass filter restrictions to get permission to transmit a radar signal on the ground from Ministry of Internal Affairs and Communications in Japan. The bandwidth of each device is presented in Table 1. The L-band band-pass filter attenuates the radar signal by more than $90 \mathrm{~dB}$ for bands outside $1257.5 \pm 120 \mathrm{MHz}$, excluding 3.3-3.9 GHz. The remnant signal (which appeared in the range of 3.3-3.9 GHz) is reduced in amplitude by the low-pass filter, which attenuates the radar signal by more than $45 \mathrm{~dB}$ for bands above $2.7 \mathrm{GHz}$.

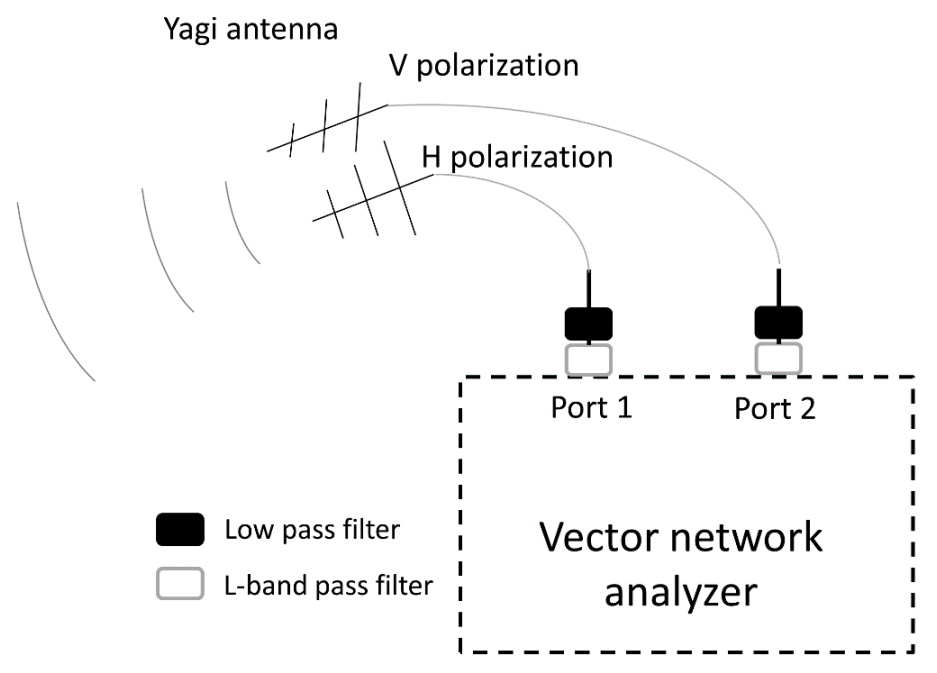

Figure 1. Ground-based radar system. 
Table 1. Bandwidth of devices.

\begin{tabular}{cc}
\hline Device & Bandwidth \\
\hline Vector network analyzer & $5 \mathrm{kHz}-6 \mathrm{GHz}$ \\
Yagi antenna & $1.26 \mathrm{GHz}-1.3 \mathrm{GHz}$ \\
L-band-pass filter & $1.215 \mathrm{GHz}-1.3 \mathrm{GHz}$ \\
\hline & $\mathrm{DC}-7 \mathrm{GHz}$ \\
Low-pass filter & Loss $<1 \mathrm{~dB}: \mathrm{DC}-1.350 \mathrm{GHz}$ \\
& Loss $>20 \mathrm{~dB}: 2.1 \mathrm{GHz}$ \\
& Loss $>45 \mathrm{~dB}: 2.7 \mathrm{GHz}$ \\
\hline
\end{tabular}

The GB-radar produced 851 pulse waves between $1.215 \mathrm{GHz}$ and $1.3 \mathrm{GHz}$, and a $85-\mathrm{MHz}$ synthetic pulse was produced to combine the 851 pulse waves. The data were taken in the frequency domain, were applied with Hanning window, and were converted to the time domain by applying an inverse Fast Fourier Transform to obtain range profiles. The original pixel spacing was $0.0223 \mathrm{~m}$. The pixel spacing was changed to $1.5 \mathrm{~m}$ to match the range of pixel spacing of the Pi-SAR-L2 data. The specifications of GB-radar and Pi-SAR-L2 are summarized in Table 2.

Table 2. Specifications of GB-radar and Pi-SAR-L2.

\begin{tabular}{ccc}
\hline & GB-Radar & Pi-SAR-L2 \\
\hline Bandwidth & \multicolumn{2}{c}{$85 \mathrm{MHz}$} \\
Height & $10-0 \mathrm{~m}$ & $6-12 \mathrm{~km}$ \\
Image width & $\sim 30 \mathrm{~m}$ & $\leq 20 \mathrm{~km}$ \\
Range resolution & $2.44 \mathrm{~m}$ (measured) & $1.76 \mathrm{~m}$ \\
Azimuth resolution & Not Available & $3.2 \mathrm{~m}(4$ look $)$ \\
Polarimetry & Full $(\mathrm{HH} / \mathrm{HV} / \mathrm{VH} / \mathrm{VV})$ \\
\hline
\end{tabular}

\subsection{Field Experiments}

Two experiments on the GB-radar system at Tsukuba space center in Japan (Table 3) were conducted for calibration and validation purposes. Two 70-cm rectangular trihedral CRs were used in the first experiment. One CR was deployed in a vacant piece of land. The other CR was deployed behind a tree (Figure 2). The GB-radar system was deployed using an aerial vehicle at $16 \mathrm{~m}$ in height. Ground-based lidar (GB-lidar) was deployed on the ground to record the exact configuration of the experiment. The specification of GB-lidar is summarized in Table 4. A GB-lidar system was also deployed using the aerial vehicle to observe the differences in attenuation between L-band SAR signals and lidar signals. Every $15 \mathrm{~min}$, observation was performed using the GB-radar system for $23 \mathrm{~h}$. The CRs were on the scene the whole time to monitor the stability of the system. The signals from the CRs are almost constant, indicating the system stability.

Table 3. Summary of two field experiments.

\begin{tabular}{ccc}
\hline & First Experiment & Second Experiment \\
\hline Date & 26-27 January 2016 & 18-19 March 2016 \\
\hline Place & \multicolumn{2}{c}{ Tsukuba Space Center } \\
\hline Calibration items & $\begin{array}{c}\text { 4 pol. Calibration } \\
(70-c m \text { corner reflector (CR)) }\end{array}$ & $\begin{array}{c}\text { 4 pol. Calibration } \\
\text { Radiometric calibration }\end{array}$ \\
\hline Measurements & $\begin{array}{c}\text { Ground-based radar } \\
\text { Ground-based lidar }\end{array}$ & $\begin{array}{c}\text { Ground-based radar } \\
\text { Anten parne SAR (Pi-SAR-L2) }\end{array}$ \\
\hline
\end{tabular}




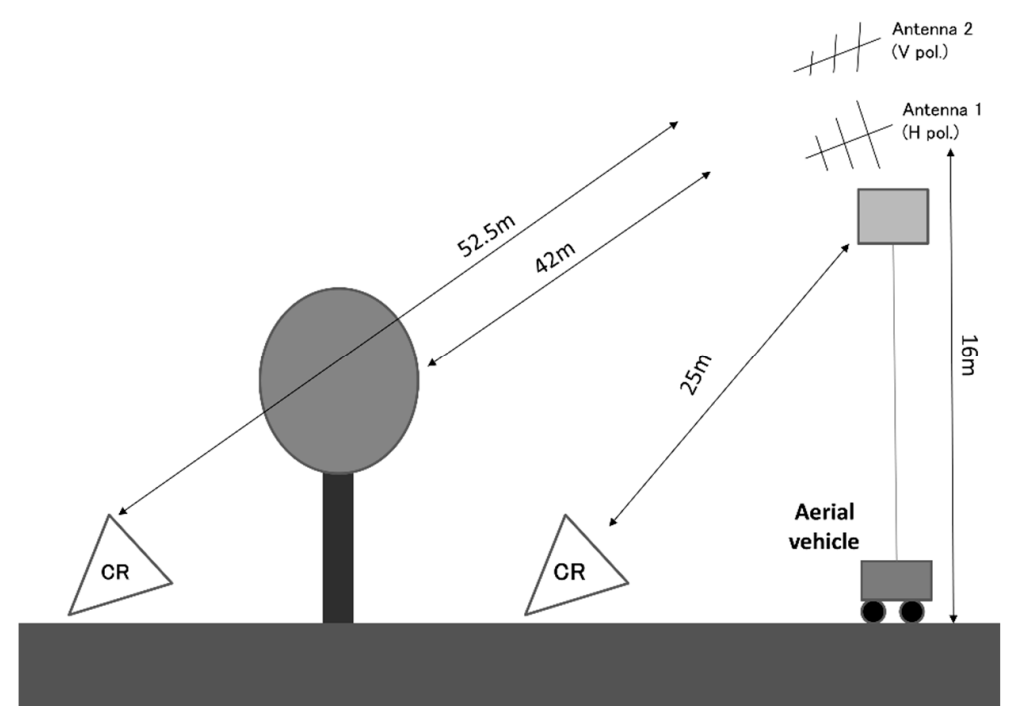

Figure 2. Configuration of the first field experiment.

Table 4. Specification of GB-LiDAR.

\begin{tabular}{cc}
\hline System & RIEGL VZ-400 \\
\hline Wavelength & Near infrared \\
Power consumption & $65 \mathrm{~W}$ \\
Pulse Repetition Frequency & $300 \mathrm{kHz}$ \\
Max. Measurement Range & $350 \mathrm{~m}$ \\
Accuracy & $5 \mathrm{~mm}$ \\
\hline
\end{tabular}

In the second experiment, forest observation was performed for $18 \mathrm{~h}$ using GB-radar. Then, the antenna was rotated to observe the $2.5-\mathrm{m}$ triangular trihedral $\mathrm{CR}$, which was deployed on a vacant piece of land (Figure 3). After the measurement, the 2.5-m CR was rotated to the north-east direction for Pi-SAR-L2 observation; Pi-SAR-L2 observed the area in the same configuration (incident angle and observation direction).

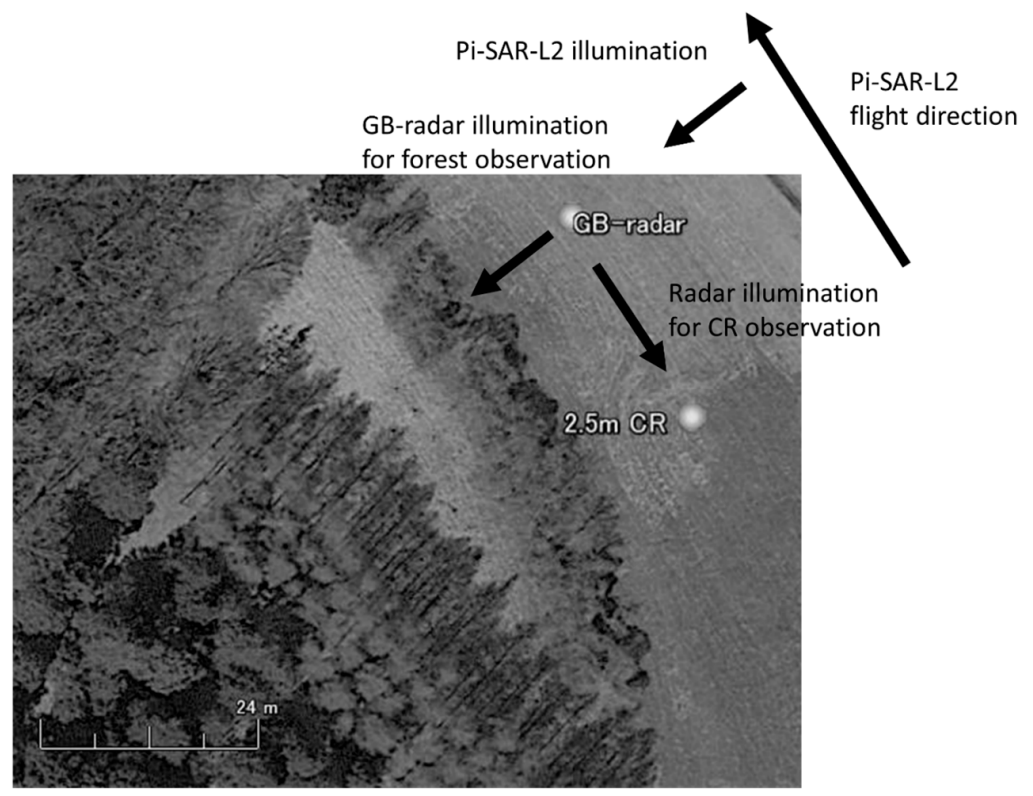

Figure 3. Configuration of the second field experiment. 


\subsection{Calibration}

The distortion matrix for the transmitting and receiving antennas is assumed to be the same. Polarimetric calibration was carried out using the following simple formula.

$$
\left[\begin{array}{ll}
M_{\mathrm{HH}} & M_{\mathrm{HV}} \\
M_{\mathrm{VH}} & M_{\mathrm{VV}}
\end{array}\right]=\left[\begin{array}{ll}
1 & \delta \\
\delta & f
\end{array}\right]\left[\begin{array}{ll}
S_{\mathrm{HH}} & S_{\mathrm{HV}} \\
S_{\mathrm{VH}} & S_{\mathrm{VV}}
\end{array}\right]\left[\begin{array}{ll}
1 & \delta \\
\delta & f
\end{array}\right]
$$

where $\delta$ is cross-talk, $f$ is the channel imbalance, $S$ represents a scattering matrix for a target, and $M$ represents an observed scattering matrix. Observation error caused by our GB-radar system is assumed to be represented by $\delta$ and $f$. $\delta$ and $f$ were obtained for each experiment. The head of the aerial vehicle, where the antenna system was deployed, was rotated for the second experiment to observe the CR and forest separately. However, the alignment of the antenna was maintained during the experiment to avoid the change of $\delta$ and $f$.

\subsection{Antenna Pattern Correction and Radiometric Calibration.}

The antenna pattern of the Yagi antenna in our system is shown in Figure 4 for the $\mathrm{E}$ and $\mathrm{H}$ plane. The range profile obtained for GB-radar was corrected based on this pattern. SAR products can be converted into a normalized radar cross section as follows:

$$
\sigma^{0}=10 \times \log _{10}\left\langle I^{2}+Q^{2}\right\rangle+C F
$$

$I$ and $Q$ are the real and imaginary parts for each pixel, and $C F$ is a calibration factor, which is determined by the $2.5-\mathrm{m} \mathrm{CR}$ signal in the second experiment. CF takes into account the effect of signal attenuation due to a mismatch of impedance between the antenna and SMA cable, and the propagation of the electro-magnetic wave after the transmission from the antenna, etc. A correction of the propagation from the $\mathrm{CR}$ position was applied for the other pixel. A theoretical radar cross-section for a triangular trihedral $2.5-\mathrm{m} \mathrm{CR}$ is defined as follows:

$$
\sigma_{\max }=10 \times \log _{10}\left(\frac{4 \pi a^{4}}{3 \lambda^{2}}\right)=34.6 \mathrm{dBm}^{2}
$$

where $a$ is the size of the CR, and $\lambda$ is the wavelength. Using this formula, CF was determined to be $109.7 \mathrm{~dB}$ in the second experiment.

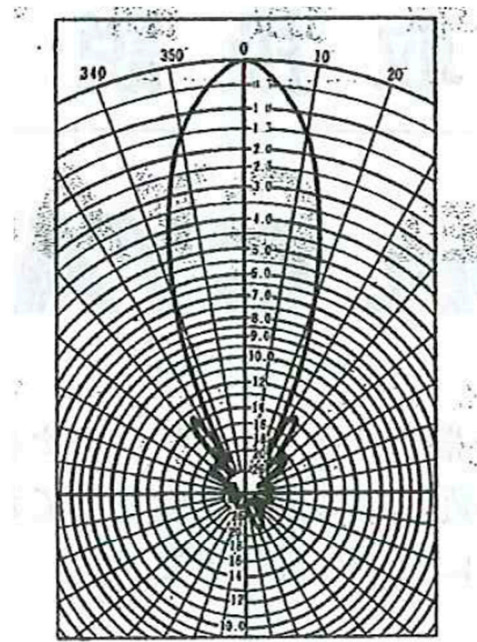

a) E-plane

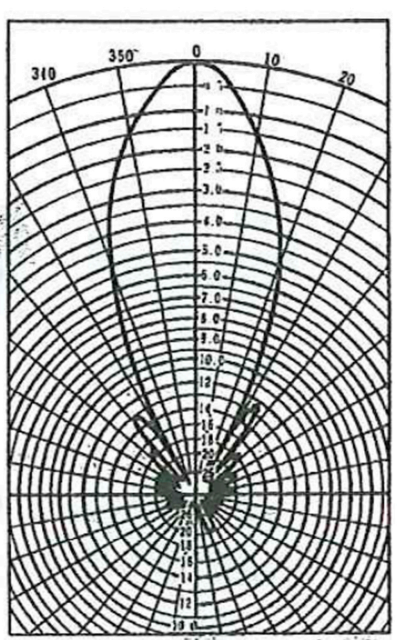

b) H-plane

Figure 4. Antenna pattern for the Yagi antenna for the GB-radar system. (a) E-plane. (b) H-plane. 
After these calibrations (polarimetric and radiometric calibration, and antenna pattern correction), range profiles were calculated for each polarimetric parameter, $\sigma^{0}(\mathrm{HH}, \mathrm{HV}, \mathrm{VV}, \mathrm{HH}+\mathrm{VV}, \mathrm{HH}-\mathrm{VV})$; polarimetric coherence $\left(\gamma_{\mathrm{HH}-\mathrm{VV}}, \gamma_{(\mathrm{HH}+\mathrm{VV})-(\mathrm{HH}-\mathrm{VV})}\right)$; eigenvalue-decomposition parameters (entropy $(\mathrm{H}) / \alpha$ /anisotropy); and four-component-decomposition parameters (double/volume/surface /helix scattering). PolSARpro software [6] was used to calculate the parameters obtained from GB-radar data and Pi-SAR-L2 data. The selected window sizes were 3 pixels for the Pi-SAR-L2 data, and 3 pixels and 18 pixels for the GB-radar data.

\section{Results and Discussion}

GB-radar range profiles before and after calibration for the first experiment are presented in Figure 5. The range profile at less than $20 \mathrm{~m}$ is affected by direct coupling between the antenna and its surroundings. In the case of $\mathrm{HH}$ and VV polarization observation, the peak of the direct coupling is observed at $0 \mathrm{~m}$. On the other hand, in the case of $\mathrm{HV}$ and $\mathrm{VH}$ polarization observation, the peak of the direct coupling is located at half the distance between then, and is observed at $2.7 \mathrm{~m}$. A signal from the $\mathrm{CR}$ in front of the tree is observed at $27 \mathrm{~m}$ in the range profile. A signal from the CR behind the tree is observed at $53 \mathrm{~m}$, and is not observed by the GB-lidar that is deployed on the aerial vehicle. The signal from the CR deployed in front of the tree is observed in HV polarization before calibration; this result indicates higher cross-talk. The signal in HV polarization is suppressed after calibration. The cross-talk and channel imbalance are improved from $-13.3 \mathrm{~dB}$ to $-30.7 \mathrm{~dB}$, and from 1.06 to 1.00 , respectively. Worse cross-talk values were observed in the second experiment. Cross-talk and channel imbalance were improved from $-14.8 \mathrm{~dB}$ to $-33.5 \mathrm{~dB}$, and from 0.66 to 1.07 , respectively, after calibration. The lower cross talk and channel imbalance of $\sim 1$ after calibration indicate that the assumption that our GB-radar system is represented by $\delta$ and $\mathrm{f}$ (Equation (1)) is valid. The values are comparable to the cross-talk value of $-31.7 \mathrm{~dB}$ and the channel imbalance of 1.013 that were obtained with PALSAR [7].
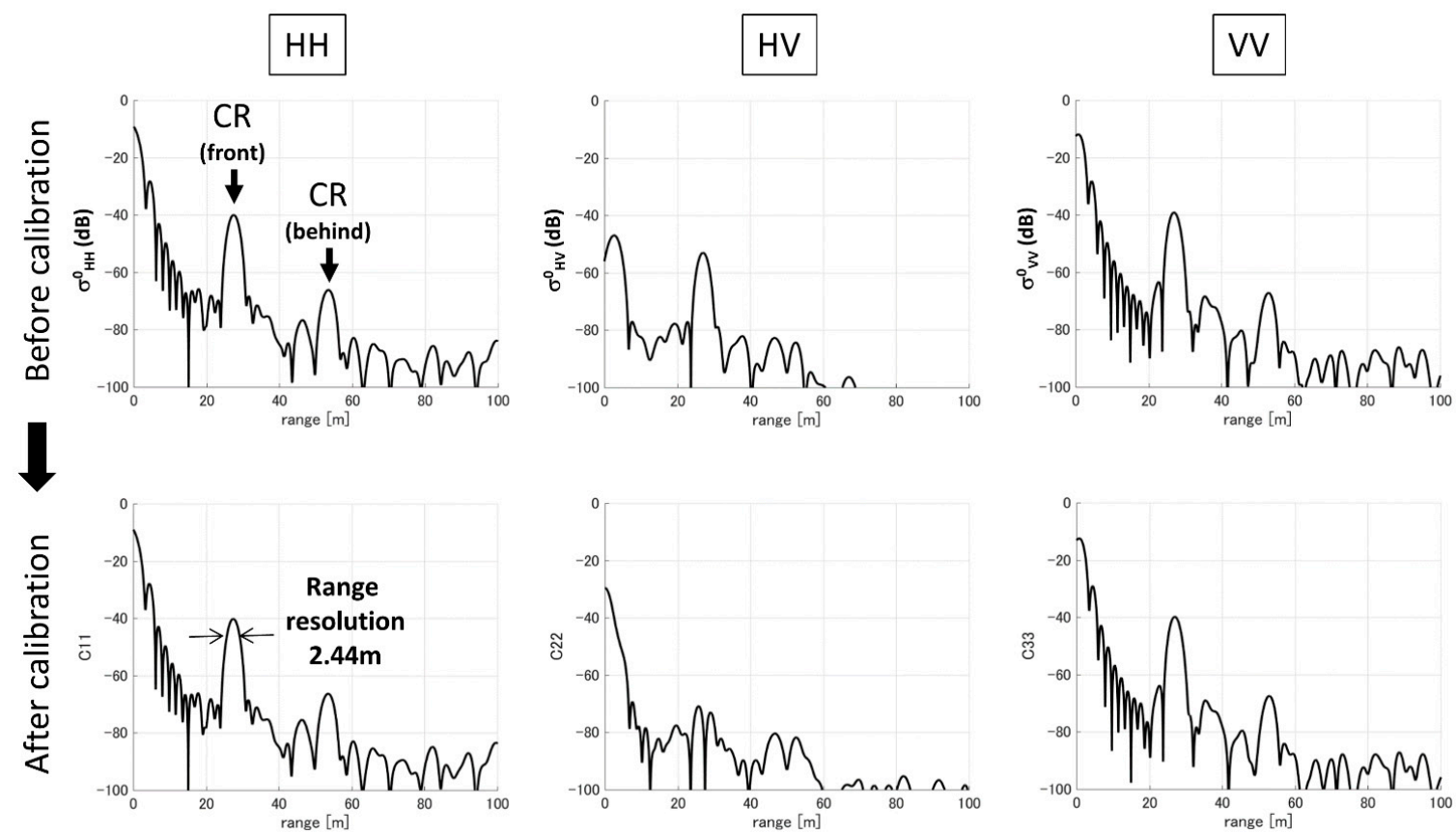

Figure 5. GB-radar range profiles before and after calibration.

The range resolution was derived from the $\mathrm{HH}$ data after calculation; it was estimated to be $2.44 \mathrm{~m}$ (Figure 5). The theoretical range resolution with an $85-\mathrm{MHz}$ bandwidth is $1.76 \mathrm{~m}$. The range resolution for the Pi-SAR-L2 estimated from the CR was approximately $1.76 \mathrm{~m}$, whereas the GB-radar system 
had worse values. Because the $85-\mathrm{MHz}$ synthetic pulse was produced from 851 pulses, the effective bandwidth may be less than $85 \mathrm{MHz}$, which may result in worse range resolution.

The range profiles for $\alpha$ and $H$ obtained in the first experiment are shown in Figure 6. $\alpha$ is approximately $0^{\circ}$ for the $\mathrm{CR}$ in front of the tree. This value indicates surface scattering, and results are consistent with theory. $\alpha$ is approximately $50^{\circ}$ for the CR behind the tree, which is a similar value as the surrounding tree canopy. On the other hand, $H$ is approximately 0 for both CRs. The radar signal from the CR behind the tree travels through the tree canopy, which may increase the $\alpha$ value, similar to radar reflection from the tree canopy. However, this situation does not significantly affect the $H$ value. The characteristics of the signals from the CRs are summarized in Table 5.
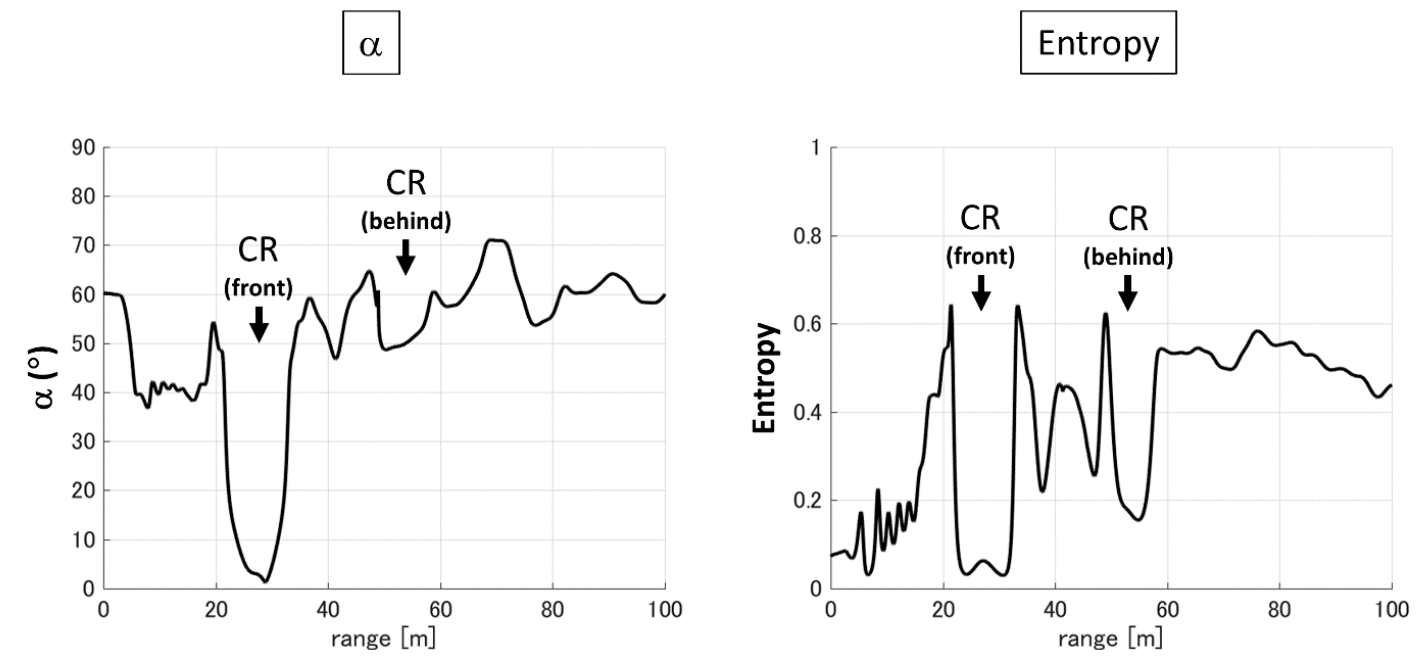

Figure 6. Range profiles of $\alpha$ and entropy obtained using GB-radar.

Table 5. Characteristics of signals from CRs.

\begin{tabular}{cccc}
\hline & & CR (in Front) & CR (Behind) \\
\hline GB-LiDAR & & Visible & Not visible \\
\hline \multirow{3}{*}{ GB-Radar (L-band) } & $\sigma^{0}$ HH & Visible & Visible \\
& Entropy & $\approx 0$ & $\approx 0$ \\
& $\alpha$ & $\approx 0$ & $\approx 50^{\circ}$ \\
\hline
\end{tabular}

Range profiles at various $\sigma^{0}$ values obtained by GB-radar over a forest are compared with that from the Pi-SAR-L2 observation in the second experiment. The results are presented in Figure 7. Standard errors were calculated using the difference between the two data sets. The standard error is 4.2 to $7.2 \mathrm{~dB}$, which shows moderate similarity. The observation time was not exactly the same, and there was a gentle wind during the observation. These different environments may induce the discrepancy between the two profiles.

The range profiles of $H / \alpha$ /anisotropy are presented in Figure 8 at window sizes of 3 pixels and 18 pixels. The GB-radar profile with a window size of 3 pixels does not match that derived from Pi-SAR-2 data. On the other hand, the GB-radar profile with a window size of 18 pixels matches the Pi-SAR-2 profile well, and the standard deviation is reduced to less than half. The independence of the radar signal for each pixel is worse for the GB-radar case, because of its worse range resolution of $2.44 \mathrm{~m}$. This situation may induce a systematically lower entropy value, and affect the other two parameters. The increase in the window size increases the entropy, and may cover the worse range resolution. 
$\underline{\mathrm{HH}}$

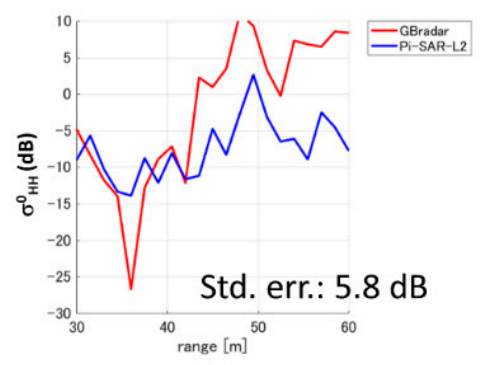

$\underline{\text { HV }}$

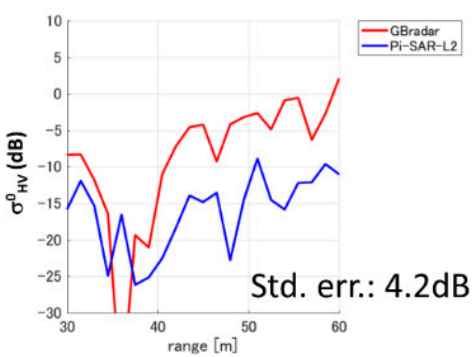

VV

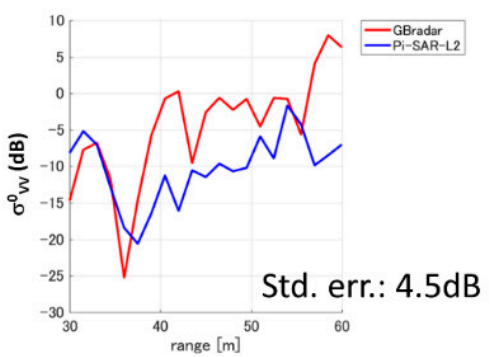

Single bounce (HH+VV)

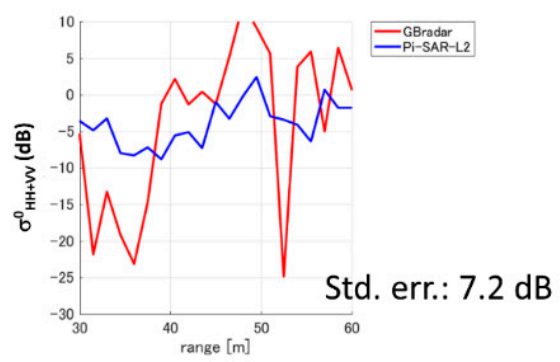

Double bounce (HH-VV)

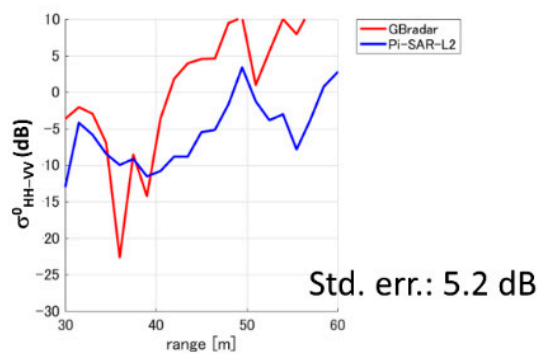

Figure 7. Range profiles of various $\sigma^{0}$ values obtained from GB-radar (red) and Pi-SAR-L2 (blue).

Entropy

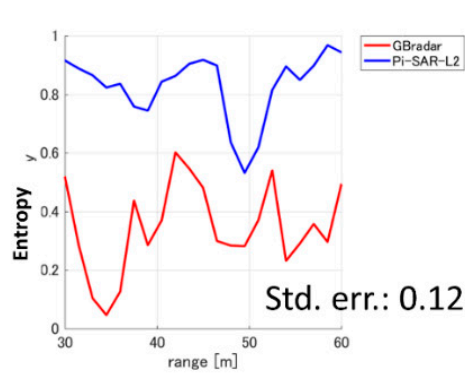

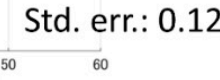

Std. err.: 0.04 $\underline{\alpha}$

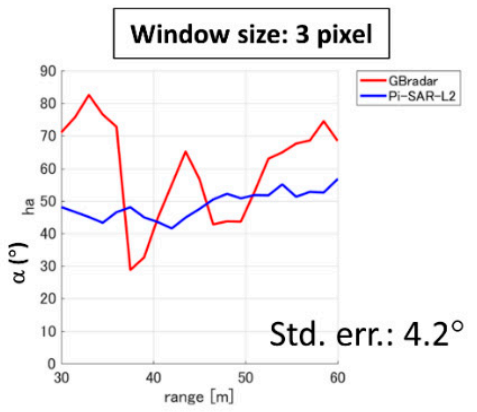

Window size: 18 pixel
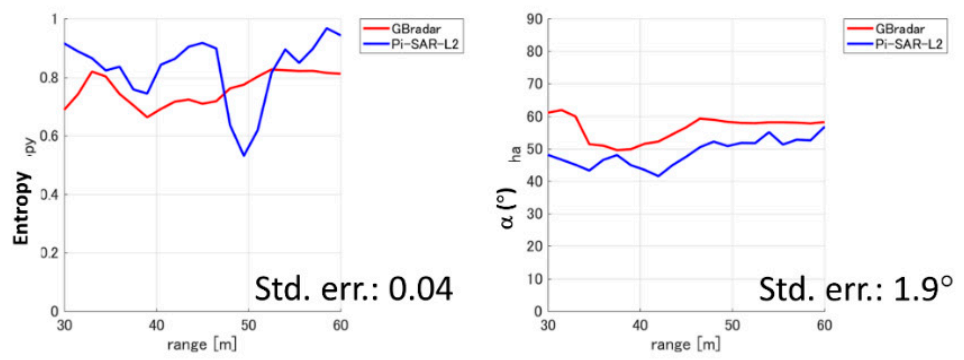

Anisotropy
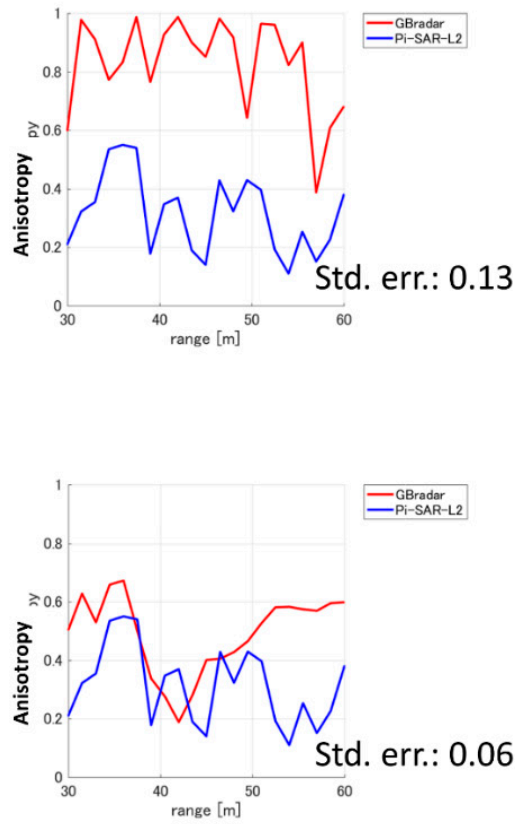

Figure 8. Range profiles at various entropy, $\alpha$; anisotropy values obtained from GB-radar (red) and Pi-SAR-L2 (blue). The window size is 3 pixels for Pi-SAR-L2 data, and 3 pixels (Top), and 18 pixels (Bottom) for GB-radar data.

Range profiles for four-component decomposition and polarimetric coherence are presented in Figures 9 and 10, respectively. Because several of the four-component-decomposition parameter values obtained from GB-radar data have a value of 0 (because of a lack of sufficient data for each pixel), the standard deviation cannot be calculated (however, the volume scattering component can 
be calculated). However, it is confirmed that a window size of 18 pixels for GB-radar data results in a better match with Pi-SAR-L2 data.

Double bounce
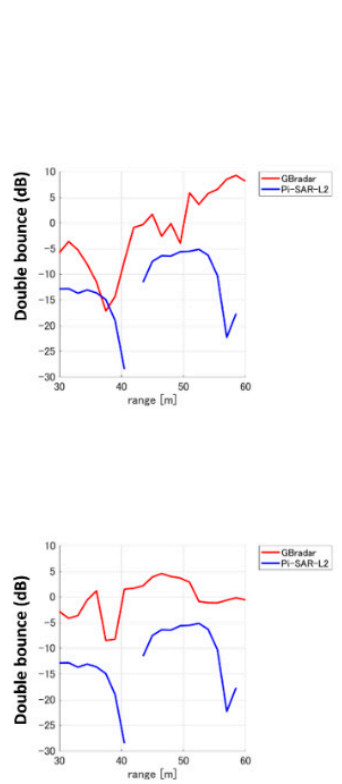

Volume

Surface

Helix

Window size: 3 pixel
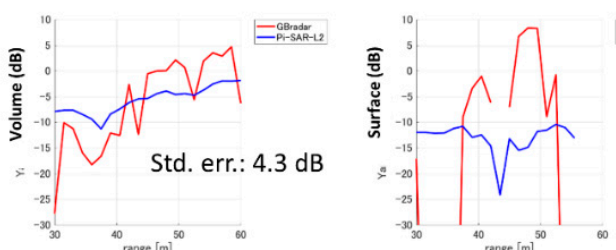

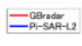

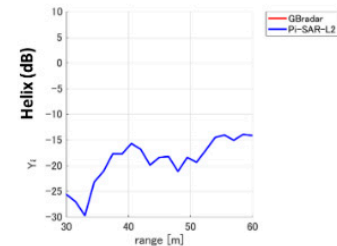

Window size: 18 pixel
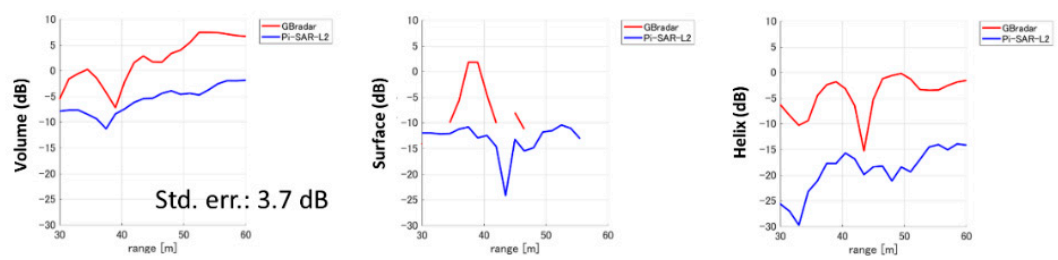

Figure 9. Range profiles of various four-component-decomposition parameters obtained from GB-radar (red) and Pi-SAR-L2 (blue).
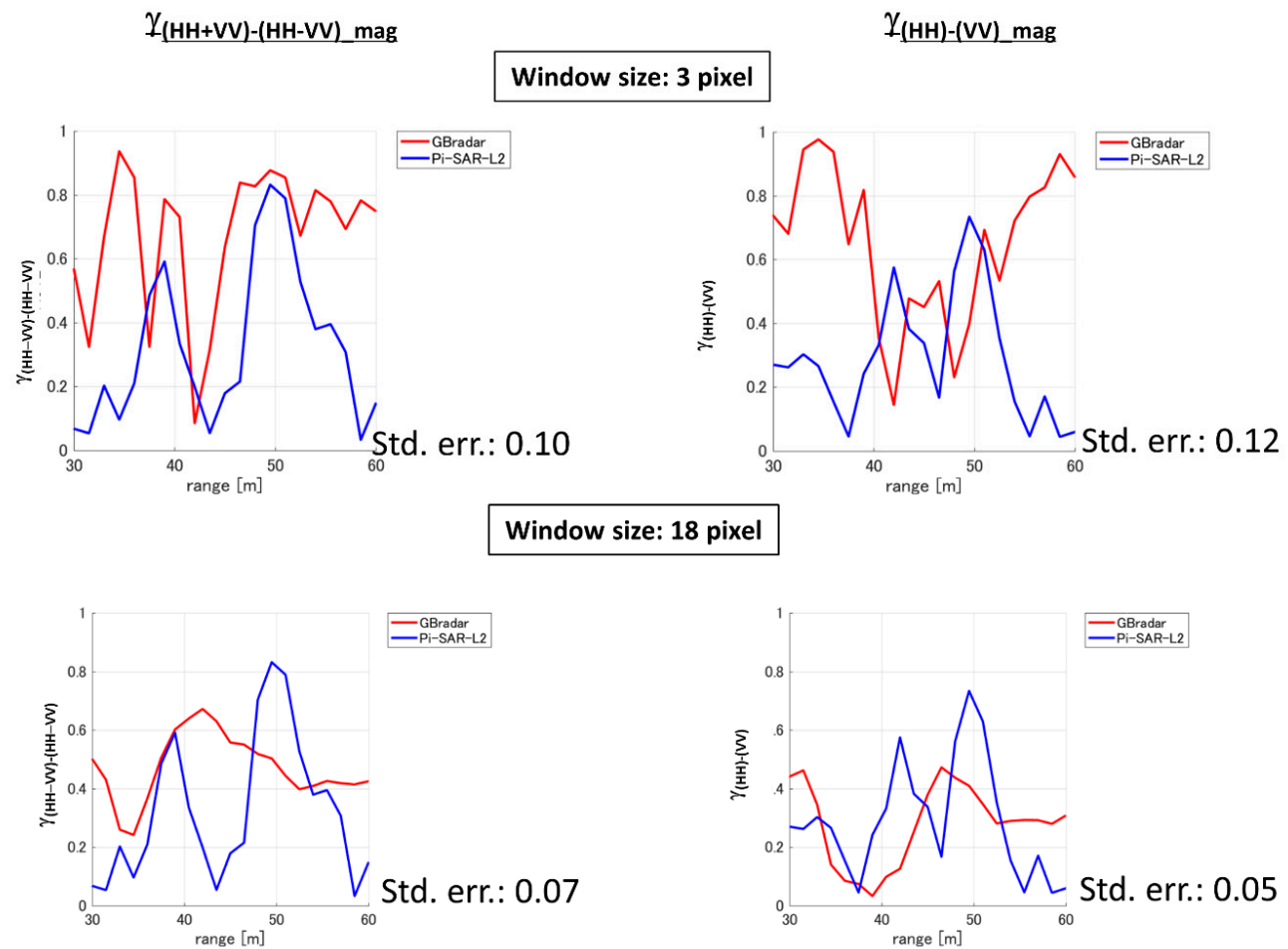

Figure 10. Range profiles of various polarimetric coherence parameters obtained for GB-radar (red) and Pi-SAR-L2 (blue). 


\section{Conclusions}

A polarimetric GB-radar system operated in the L-band has been developed. The frequency range is 1.215 to $1.3 \mathrm{GHz}$, which is the same as that of satellite-borne-SAR (PALSAR-2) and air-borne SAR (Pi-SAR-L2). Polarimetric calibration and forest observation were carried out twice in a field so as to calibrate and validate the GB-radar data. After the calibration, the cross-talk is $-30.7 \mathrm{~dB}$ and $-33.5 \mathrm{~dB}$ and the channel imbalance is 1.00 and 1.07 for the first and second experiments, respectively. These values are comparable to $-31.7 \mathrm{~dB}$ and 1.013 , which were obtained using PALSAR. Radiometric calibration and antenna pattern correction were also carried out for the second experiment. Near simultaneous GB-radar and Pi-SAR-L2 observation were carried out for the forested area. The range profiles obtained by GB-radar and Pi-SAR-L2 were compared for several polarimetric parameters, namely, radar backscattering coefficient $\left(\sigma^{0}\right)$, polarimetric coherence, eigenvalue-decomposition parameters, and four-component-decomposition parameters. The two range profiles matched moderately well. The observation time was not the same and there was a gentle wind during the observation, which might have caused the discrepancy between the profiles. The experiment shows sufficiently good performance that can compensate for the limited possibility of satellite/air-borne SAR observation.

Acknowledgments: This research was supported by the research budget of JAXA (previously, the author belonged to JAXA). The research results will be used for the JJ-FAST system, funded by JICA (Japan International Cooperation Agency, Tokyo, Japan) and JAXA, and will be used for early deforestation detection in global tropical forests.

Author Contributions: Manabu Watanabe conceived, designed, and performed the experiments, analyzed the data, wrote the paper. Masanobu Shimada contributed to discussion and interpretation of the results.

Conflicts of Interest: The authors declare no conflicts of interest.

\section{References}

1. Watanabe, M.; Motohka, T.; Shiraishi, T.; Thapa, R.B.; Yonezawa, C.; Nakamura, K.; Shimada, M. Multi-temporal fluctuations in L-band backscatter from a Japanese forest. IEEE Trans. Geosci. Remote Sens. 2015, 53, 5799-5813. [CrossRef]

2. Lucas, R.; Armston, J.; Fairfax, R.; Fensham, R.; Accad, A.; Carreiras, J.; Kelley, J.; Bunting, P.; Clewley, D.; Bray, S.; et al. An evaluation of the ALOS PALSAR L-band backscatter-Above ground biomass relationship Queensland, Australia: Impacts of surface moisture condition and vegetation structure. IEEE J. Sel. Top. Appl. Earth Obs. Remote Sens. 2010, 3, 576-593. [CrossRef]

3. Watanabe, M.; Nagai, H.; Natsuaki, R.; Shimada, M. Phase shift observed over a forest stand with PALSAR-2 SAR interferometry in Hakone. In Proceedings of the Japan Geoscience Union Meeting 2016, STT54-9, Tokyo, Japan, 22 May 2016.

4. Yueh, S.H.; Kong, J.A. Calibration of polarimetric radars using in-scene reflectors. J. Electromagn. Waves Appl. 1990, 4, 27-48. [CrossRef]

5. Gau, J.-R.J.; Burnside, W.D. New polarimetric calibration technique using a single calibration dihedral. IEEE Proc. Microw. Antennas Propag. 1995, 1421, 19-25. [CrossRef]

6. Pottier, E.; Ferro-Famil, L.; Allain, S.; Cloude, S.; Hajnsek, I.; Papathanassiou, K.; Moreira, A.; Williams, M.; Minchella, A.; Lavalle, M.; et al. Overview of the PolSARpro V4.0 software: The open-source toolbox for polarimetric and interferometric polarimetric SAR data processing. Proc. IEEE Int. Geosci. Remote Sens. Symp. 2009, 4, 936-939.

7. Shimada, M.; Isoguchi, O.; Tadono, T.; Isono, K. PALSAR radiometric and geometric calibration. IEEE Trans. Geosci. Remote Sens. 2009, 4712, 3915-3932. [CrossRef]

(C) 2017 by the authors. Licensee MDPI, Basel, Switzerland. This article is an open access article distributed under the terms and conditions of the Creative Commons Attribution (CC BY) license (http:/ / creativecommons.org/licenses/by/4.0/). 